\title{
The Education Quality Improvment Practical Exploration of Applied Chemistry Experiments in Xi'an Shiyou University
}

\author{
Weichao Du*, Tong Shao, Huafeng Li, Jie Zhang, Gang Chen, Sanbao Dong, Dan \\ Xue
}

School of Chemistry and Chemical Engineering, Xi'an Shiyou University, Xi'an, Shaanxi 710065, China

${ }^{*}$ Corresponding author.Email: duweichao@xsyu.edu.cn

\begin{abstract}
Under the new situation, the rapid development of the petroleum industry has increasingly required the quality and quantity of chemical talents in oil fields. "Oil and Gas Field Applied Chemistry Experiment" is an extremely important part of Xi'an Shiyou University's applied chemistry training program. It plays the role of a bridge between theoretical learning and applied practice, and this course is of great importance to students of applied chemistry. In order to improve the teaching quality of Oil and Gas Field Applied Chemistry Experiment, this article takes Xi'an Shiyou University as an example. Based on the teaching experience of Oil and Gas Field Applied Chemistry Experiment in recent years, the author analysed the problems of academic performance and composition about the teachers, teaching materials, instruments and students, and corresponding practical explorations are put forward. It is expected to provide a certain theoretical basis for the teaching reform of the course of "Oil and Gas Field Applied Chemistry Experiment " of our school, and provide some reference for related disciplines of domestic petroleum colleges.
\end{abstract}

Keywords: Teaching reform, experimental curriculum, practical exploration, applied chemistry, appxlied chemistry in oil and gas fields

\section{INTRODUCTION}

In the petroleum industry, the science and technology of applying chemicals and chemical methods in oil (gas) field exploration, drilling (completion), mining, and gathering and transportation are generally called oil and gas field applied chemistry. The "Oil and Gas Field Applied Chemistry" course is an extremely important theoretical course in petroleum universities. It is based on petroleum engineering, chemistry, chemical engineering, mass and heat transfer, and involves corrosion engineering, environmental protection engineering and microbiology, It is an emerging application discipline that requires knowledge of multiple disciplines [1,2]. As a further supplement and practical support for the course, the "Experiment of Applied Chemistry Specialty" course serves as the most direct link between theoretical study and applied practice. The importance of this course for students of applied chemistry in our school is self-evident. The School of Chemistry and Chemical Engineering of Southwest Petroleum University, a training base for oilfield chemistry talents in China, has a total of 40 academic hours in the "Oilfield Applied Chemistry", while the "Experiment in Applied Chemistry" is 24 hours and is a required course in the elective courses of applied chemistry. Our school's oilfield chemistry courses include two theoretical courses: "Oilfield Chemistry Process" and "Oilfield Chemistry Principles". The "Applied Chemistry Specialty Experiment" course is 32 hours and this course is a required course for applied chemistry. There are a total of eight experiments in the "Experiment of Applied Chemistry" course of Xi'an Petroleum University: emulsification experiment and performance evaluation of demulsifier, oilfield wastewater treatment experiment, preparation and effect evaluation of oil layer acidizing and deblocking agent, crude oil anti-wax effect test, Waterbased fracturing fluid crosslinking and gel breaking, drilling fluid preparation and performance testing, experimental oil well cement performance and admixture evaluation, and oil well water blocking agent preparation and evaluation. This course is very important for cultivating practical skills for students of applied chemistry. In recent years, with the rapid development of the oil industry, oilfield exploration and development, drilling, storage, transportation and refining and chemical companies have increasingly demanded the hands-on practical ability of oilfield chemistry graduates from petroleum colleges and universities to analyze and solve production problems in oilfields. As an oil university that trains students, the corresponding adjustments should be made in aspects such as the training methods and contents of experimental courses [3, 4].

Xi'an Petroleum University is the only multi-disciplinary university with petroleum and petrochemical characteristics in northwestern China. It has great influence in the petroleum industry and has become an important talent base for China's petroleum and petrochemical industry. In the northwest region, there are many second-level units of large oil state-owned 
enterprises such as PetroChina and Sinopec. Shaanxi Province also has two large oil companies with PetroChina Changqing Oilfield Branch Company and Yanchang Petroleum Group Company, which have the autonomy of oil exploration and development. It provides a unique stage for the talents of applied chemistry graduates of our school to display their talents and professional expertise. At the same time, the continuous development of advanced oilfield science and technology requires that graduates of applied chemistry in our school not only have a complete theoretical knowledge of the system, but also hope that graduates can achieve the "order-based" training needs that can be used on the job after practical operation in the school. According to the feedback from interviews with employers and graduates of applied chemistry, the graduates of applied chemistry majors working in chemistry positions in oil and gas fields have solid theory and high scientific literacy. However, there are still feedbacks from human units that our school 's graduates in applied chemistry are not able to combine the knowledge of oil fields and textbooks well in oilfield production, and the shortcomings of the ability to improve hands-on operation still need to be improved. Moreover, the ability to deal with the latest oilfield chemistry problems involved in the "up-middle-down" journey of oil and gas production is still lacking.

In order to improve the teaching quality of the "Applied Chemistry Specialty Experiment" course, the author takes Xi'an University of Petroleum as an example. Based on the teaching experience of the "Oil and Gas Field Applied Chemistry Experiment" course in recent years, the author analyzes some problems that still exist in teachers, teaching materials, instruments, students and score composition in the course of the course teaching, and carries out corresponding practical exploration and puts forward improvement measures. In this way, I hope to provide some suggestions for the teaching quality of the "Experiment of Applied Chemistry" course in our school, and to provide reference for the development of related disciplines of domestic petroleum colleges

\section{COURSE INFORMATION}

\subsection{Teacher}

The course preparation teachers and lecture teachers of the "Applied Chemistry Specialty Experiments" are made up of $\mathrm{PhD}$ teams under the age of 45 . They are young and powerful, they are responsible and can devote themselves to their work wholeheartedly, which has played a good role in taking the lead in learning and guiding students. However, there are still improvements in the process of experimental teaching. For example, the interaction with students needs to be further strengthened. Textbooks and blackboards should be combined in the teaching of experimental principles, so as to more vividly display deeper on-site operations. The principle part of the experimental instrument should be explained during the use of the instrument and during the demonstration operation. For example, when measuring the rheology of drilling fluid, a six-speed rotary viscometer is needed. When explaining the following viscosity calculation formulas (as shown in formula 1, formula 2 and formula 3 ), the principle of the experimental instrument should also be explained, as shown in Figure 1. Therefore, to deepen the impression of the students, it serves the purpose of narrowing the drilling site and extending the knowledge classroom as follows [5, 6].

Apparent viscosity $\mathrm{AV}=1 / 2 \varphi 600$

Plastic viscosity $\quad P V=\varphi 600-\varphi 300$

Yield point $\quad \mathrm{YP}=\mathrm{AV}-\mathrm{PY}$

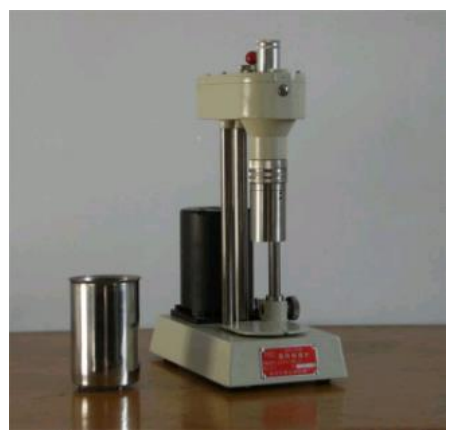

Figure 1 Six-speed rotary viscometer

\subsection{Teaching materials}

At present, the textbook "Experiment in Applied Chemistry" is written by our school's oilfield chemistry course group, and the writing is completed earlier. The advantage of this textbook is that it focuses on the cultivation of students' theoretical knowledge, and the description of basic experimental operations is detailed. But in recent years, the application of chemical technology in oil and gas fields has developed rapidly. On the basis of emphasizing basic operations, the latest technology of today 's oil fields should be excerpted and written into this textbook, so that students can get clear access to the latest developments in oilfield chemistry and cutting-edge technology through this book. For example, in the drilling fluid preparation and performance test experiment project, nano-drilling fluid evaluation steps and drilling fluid plugging content and evaluation methods can be added. In the crosslinking and gel breaking of water-based fracturing fluid, the concept and evaluation method of slippery water can be appropriately added. In the latest research content of intelligent water plugging can be added in the preparation and evaluation of oil well water plugging agent. 


\subsection{Instruments}

The Applied Chemistry Specialty Laboratory is currently set up in the Laboratory 303, Department Building, School of Chemistry and Chemical Engineering, Huyi Campus. The laboratory has a wide experimental area, and currently can basically meet the smooth progress of the Applied Chemistry Specialty Experiment. However, large instruments still have problems of low accuracy and outdated instruments. For example, in the emulsification experiment and demulsifier performance evaluation experiment, due to the lack of large container equipment that can hold hot water, currently only the bottom of the test tube invades into the hot water. To a certain extent, it affects the accuracy of experimental teaching and student operation, which in turn affects the analysis of experimental results. In the preparation of drilling fluids and performance test experimental projects, the current instruments can only meet the measurement of rheology, density, and loss of wall at room temperature and pressure. However, due to the lack of corresponding instruments, high-temperature and high-pressure water loss wallmaking properties, lubricity and inhibitory experiments could not be carried out. In the water-based fracturing fluid cross-linking and gel-breaking experimental project, due to the lack of HAAKE viscometer, at present, we can only rely on the "pick-hang experiment" to qualitatively observe the effect of cross-linking and gel breaking. Therefore, it is recommended that the relevant person in charge should raise funds from multiple channels, and then add and replace high-precision instruments and equipment corresponding to the experimental project to improve the precision and accuracy of the instrument, so as to better cultivate students' hands-on operation and on-site understanding ability.

\subsection{Students}

Teachers and students are the main body of the experiment, and the success of the experiment depends largely on the student's state, preview situation and interest level. Judging from the author's teaching experience for several years, after studying the theoretical lessons in Oil and Gas Field Chemistry and Principles of Oil and Gas Field Chemistry, the students have a deep understanding of oil field chemistry. However, lazy, overwhelmed and "indifferent" learning mentality appeared in the experimental class. After discussion with students, it was found that the main reasons for this phenomenon are as follows: (1) In the face of postgraduate entrance examination, a large part of everyone's attention, time and energy are in the review of postgraduate entrance examination subjects; (2) Did not study in advance and did not understand the purpose and operation process of the experimental project; (3) "I will not work in the petroleum unit in the future, and studying oilfield chemistry will not help me in future development." In view of the above problems, it is recommended to carry out the experiment of applied chemistry major at the beginning of the fourth grade of the university in the future, so as to put an end to the "lazy wind" and "indifferent" mentality of students.

\subsection{Composition of achievements}

The final score of the "Experiment in Applied Chemistry" course is composed of two parts: theoretical examination and daily scores. Among them, daily scores account for $70 \%-80 \%$, and theoretical scores account for 20\%-30\%. The daily scores are composed of four parts: preview, operation, recording and report for each experiment. The questions in the theoretical examination are the precautions and basic theory of the key steps in the experiment. Open-book examination is adopted in the examination, and the examination questions include five discussion questions. This traditional method of assessing achievement can be relatively fair, just and objective, but it does not fully reflect the actual level of students' experiment, nor can it actually cultivate students' interest in learning. In order to solve this problem, it is suggested that the interaction between the lecturer and the receiver should be included in the assessment items of the usual score in the later experimental process teaching and score composition. In addition, considering the addition of the test of the experiment, when all the experiments are completed, the students will draw lots to decide which experiment to take, and the teacher will score accordingly. The final score of this course is changed to usual score + experimental test score + theoretical test score. To a certain extent, this measure focuses on examining the operation level of students in the experimental process, which can greatly stimulate students' interest in operation.

\section{CONCLUSION}

Under the current new situation, with the continuous increase in international oil prices and the steady increase in the proportion of oil and natural gas in the national economy, the country is increasing its exploration and development efforts for oil in the northwest of China. Many of the core oil and gas field chemical problems involved in this process have put forward unprecedented requirements for the capabilities and qualities of relevant practitioners. Graduates of applied chemistry from Xi'an Shiyou University have unique advantages in employment and employment channels. The degree of student ability can in turn affect the company's impression and support to our school. The course "Experiment of Applied Chemistry" is extensive and extremely complicated. The improvement of the teaching quality of this course requires not only close cooperation between teachers and students, but also constant innovation of teaching theories, techniques and methods. Only by fully recognizing this point can we continue to explore new teaching modes and methods suitable for this course to meet the needs of 
cultivating high-quality and high-standard oilfield chemistry professionals under the new situation.

\section{ACKNOWLEDGMENT}

The authors would like to thank "the Opening Fund of Shandong Key Laboratory of Oilfield Chemistry", "the Fundamental Research Funds for the Central Universities (19CX05006A)" and "Natural Science Basic Research Program of Shaanxi (Program No. 2020JQ-785)" for financial support.

\section{REFERENCES}

[1] G. Chen, M.L. Gao, X.Y. Wang, J. Zhang. Comprehensive Experimental Design for Evaluation of Surfactants Used in Oilfield, Advances in Social Science, Education and Humanities Research., 425 (2020) 124-129.

[2] X.X Liu, Y. Sun, H. Sun, S.J. Li, J. Zhang and G. Chen. Quantitative Analysis and Performance Evaluation of Lignosulfonate as a Comprehensive Experimental for Environmental Education, Advances in Social Science, Education and Humanities Research., 425 (2020) 130-134.

[3] G. Chen, Z.Z. Zhou, Y.K. Chen, X.Y. Zhao, Q.Q. Han, X.T. Yin, Y.L.Zang. Evaluation of Crude Oil Rheology as a Comprehensive Experimental for the Applied Chemistry Education, Advances in Social Science, Education and Humanities Research., 425 (2020)135-143.

[4] W.C. Du, X.Y. Wang, G. Chen, J. Zhang, M. Slaný. Synthesis, property and mechanism analysis of a novel polyhydroxy organic amine shale hydration inhibitor, Minerals., 10 (2020) 128-142.

[5] W.C.Du, X.L. Pu, J.S. Sun, X. Luo, Y.N. Zhang, L. Li. Synthesis and evaluation of a novel monomeric amine as sodium montmorillonite swelling inhibitor. Adsorpt. Sci. Technol., 36 (2018) 655-668.

[6] W.C. Du, M. Slaný, X.Y. Wang, G. Chen, J. Zhang. The Inhibition Property and Mechanism of a Novel Low Molecular Weight Zwitterionic Copolymer for Improving Wellbore Stability, Polymers., 12 (2020) 708-721. 